\title{
Correction to: Pharmacoepidemiology resources in Ireland- an introduction to pharmacy claims data
}

\author{
Sarah-Jo Sinnott ${ }^{1}$ Kathleen Bennett ${ }^{2}$ - Caitriona Cahir ${ }^{2}$
}

Published online: 26 October 2017

(C) Springer-Verlag GmbH Germany 2017

\section{Correction to: Eur J Clin Pharmacol}

https://doi.org/10.1007/s00228-017-2310-7

In the $3^{\text {rd }}$ paragraph and $2^{\text {nd }}$ line of the Conclusion section the correct sentence should be: It is now important to encourage policy and decision makers to facilitate and accommodate future linkage of data.

The original article was corrected.

The online version of the original article can be found at https://doi.org/ 10.1007/s00228-017-2310-7

Sarah-Jo Sinnott

sarah-jo.sinnott@1shtm.ac.uk

1 Department of Non-communicable Disease Epidemiology, London School of Hygiene and Tropical Medicine, Keppel St,

London WC1E 7HT, UK

2 Division of Population Health Sciences, Royal College of Surgeons Ireland, Dublin, Ireland 